\title{
Botanical authentication of globe artichoke-containing foods: Differentiation of Cynara scolymus by a novel HRM approach
}

\author{
Liliana Grazina ${ }^{a}$, Andreia Batista ${ }^{\mathrm{a}}$, Joana S. Amaral ${ }^{\mathrm{b}}$, Joana Costa ${ }^{\mathrm{a}}$, Isabel Mafra ${ }^{\mathrm{a},}$ \\ ${ }^{\text {a }}$ REQUIMTE-LAQV, Faculdade de Farmácia, Universidade do Porto, Rua de Jorge Viterbo Ferreira, 228, 4050-313 Porto, Portugal \\ ${ }^{\mathrm{b}}$ Centro de Investigação de Montanha (CIMO), Instituto Politécnico de Bragança, Campus de Sta. Apolónia, 5301-857 Bragança, Portugal
}

\section{A R T I C L E I N F O}

\section{Keywords:}

Globe artichoke

Plant food supplements

Authenticity

Real-time PCR

High-resolution melting analysis

\begin{abstract}
A B S T R A C T
Cynara scolymus L., known as globe artichoke, is a medicinal plant widely used in plant food supplements (PFS) and herbal infusions due to its beneficial health properties. The high demand for artichoke-containing products can lead to adulteration practices. In this work, a real-time polymerase chain reaction (PCR) system coupled to high-resolution melting (HRM) analysis was proposed to differentiate C. scolymus from other Cynara species. Hence, a Cynara-specific real-time PCR assay was successfully developed with high analytical performance, achieving a sensitivity of $0.4 \mathrm{pg}$ of globe artichoke DNA. HRM analysis enabled the discrimination of $C$. scolymus, with a high level of confidence $(>98 \%)$, corroborating sequencing data. Application results to artichokecontaining PFS and mixed herbal infusions allowed confirming the presence of $C$. scolymus in $38 \%$ of the samples, suggesting the substitution/mislabelling of globe artichoke in 2 samples and the need for further efforts to increase DNA amplifiability of PFS.
\end{abstract}

\section{Introduction}

Cynara scolymus, commonly known as globe artichoke, is one of the botanical species with medicinal properties, frequently included in plant food supplements (PFS) (Garcia-Alvarez et al., 2016). It is a perennial plant species from the Asteraceae family, being a basionym of Cynara cardunculus subsp. scolymus L. Hegi, and Cynara cardunculus var. scolymus L. Benth (IPNI, 2021). The nutritional and medicinal properties of artichoke are mainly related to the chemical composition of the head and leaves, which are recognised as natural sources of phenolic acids, such as chlorogenic acid and cynarin, and rich in flavonoids, namely apigenin and luteolin (El Senousy, Farag, Al-Mahdy, \& Wessjohann, 2014; Pereira, Barros, \& Ferreira, 2014; Ruiz-Cano et al., 2014). These phytochemicals are responsible for the choleretic, hepatoprotective, antimicrobial, antioxidant and anticancer activities, as well as diuretic and hypocholesterolemic properties (El Senousy et al., 2014; EMA, 2018; Ruiz-Cano et al., 2014; Turkiewicz, Wojdyło, Tkacz, Nowicka, \& Hernández, 2019). Besides, C. scolymus blossom discs accumulate inulin, an important dietary fibre, which works as a prebiotic (Morris \& Morris, 2012; Ruiz-Cano et al., 2014). Among several effects, artichoke is also capable of improving lipid metabolism and digestive elimination functions, being widely included in food supplements for body weight control and/or for overweight/obesity (EMA, 2018; Garcia-Alvarez et al., 2016). Consequently, the high demand for C. scolymus-containing products makes them potential adulteration targets. Such practices could be unintended by the inadvertent misidentification due to morphologic similarities among some species, or even intentional by the deliberate addition or substitution with other species of lower commercial value. Both cases can result in misleading or even harmful effects on consumer's health and well-being, making it imperative to develop methods to authenticate the botanical origin of globe artichokecontaining products.

Analytical methodologies, such as chromatography, spectroscopy, among others, have been used to assess the authenticity of PFS. Pereira et al. (2014) reported the use of liquid and gas chromatography to distinguish artichoke, milk thistle and borututu, based on their chemical profiles. However, these methods rely on the chemical composition of the plant, which can vary with the physiological conditions of the plant and part used, geographical location, storage, processing and climate, among other factors. Furthermore, chemical analysis can be of limited application in the cases of complex matrices, such as PFS, since they undergo processing and generally contain mixtures of several medicinal plants (Costa et al., 2015; Grazina, Amaral, \& Mafra, 2020; Heubl, 2010).

\footnotetext{
* Corresponding author.

E-mail address: isabel.mafra@ff.up.pt (I. Mafra).
} 
In contrast, DNA-based methods have been reported as suitable tools for the authentication of botanical products as PFS, being independent of environmental, physiological, storage and processing conditions. The advantages of these methods are related to the high thermal stability of the DNA molecules and their ubiquity in all cells (Costa et al., 2015; Grazina et al., 2020). Moreover, DNA sequences are specific of each individual, enabling the identification and differentiation, even in closely related species (Franz, Chizzola, Novak, \& Sponza, 2011). Several techniques based on DNA analysis have been proposed to identify, authenticate and even quantify DNA species in botanical products (Grazina, Amaral, Costa, \& Mafra, 2020; Grazina et al., 2020). Among them, DNA barcoding is the most popular, which has been widely applied in the authentication of medicinal plants, herbal products and PFS (Grazina et al., 2020; Howard, Lockie-Williams, \& Slater, 2020; Veldman et al., 2020; Zhang et al., 2020). However, it relies on Sanger sequencing targeting barcode sequences of around $500 \mathrm{bp}$, which can be a limitation in the case of samples containing highly processed plant material, such as the PFS. More recently, high-resolution melting analysis (HRM) has emerged as a specific, reliable and cost-effective tool to distinguish closely related species or even cultivars, without requiring further sequencing analysis. This technique relies on the gradual denaturation of the double-stranded DNA, which allows detecting small nucleotide differences (Costa et al., 2016; Druml \& Cichna-Markl, 2014; Grazina et al., 2020; Grazina, Costa, Amaral, \& Mafra, 2021; Xanthopoulou et al., 2016). Besides, it targets informative short sequences ( $<300 \mathrm{bp}$ ) from nuclear, plastidial or mitochondrial regions, which is a major advantage to analyse processed samples containing degraded DNA (Grazina et al., 2020; Sun, Li, Xiong, Zhao, \& Chen, 2016). HRM analysis has already been developed to discriminate several plant species in complex matrices and to successfully authenticate commercial herbal products and PFS (Costa et al., 2016; Jung, Kim, Yang, Bang, \& Yang, 2014; Li et al., 2018; Mishra, Shukla, \& Sundaresan, 2018; Osathanunkul \& Madesis, 2019; Osathanunkul, Osathanunkul, \& Madesis, 2018; Song, Li, Xiong, Liu, \& Liang, 2016). However, to our knowledge, methods on the specific identification of $C$. scolymus or its discrimination from other closely related species have not yet been reported.

Hence, this work aimed at developing, for the first time, a method for the identification of C. scolymus and its differentiation from other related

Table 1

Results of end-point PCR and real-time PCR coupled to HRM analysis applied to commercial samples of plant food supplements and herbal infusions.

\begin{tabular}{|c|c|c|c|c|c|c|c|}
\hline \multirow[t]{2}{*}{ Code } & \multirow[t]{2}{*}{ Sample } & \multirow[t]{2}{*}{ Relevant labelled information } & \multicolumn{2}{|c|}{ End-Point PCR } & \multirow{2}{*}{$\begin{array}{l}\text { Real-time } \\
\text { PCR } \\
\mathrm{Cq}^{\mathrm{a}, \mathrm{b}}\end{array}$} & \multicolumn{2}{|c|}{ HRM analysis } \\
\hline & & & Eukaryotes & $\begin{array}{l}\text { CyC-F1/ } \\
\text { CyC-R1 }\end{array}$ & & Cluster & $\begin{array}{l}\text { Level of } \\
\text { confidence }^{b}\end{array}$ \\
\hline$\# 1$ & Capsules (draining) & C. scolymus (109 mg per capsule) & + & - & & & \\
\hline$\# 2$ & Capsules (weight reducer) & $\begin{array}{l}\text { C. scolymus (dried extract with } 2.5 \% \text { cynarin, } 600 \mathrm{mg} \text { per } \\
\text { capsule), S. marianum (dried extract) }\end{array}$ & + & - & & & \\
\hline \#3 & Capsules (weight loss) & C. scolymus (100 mg per capsule) & + & - & & & \\
\hline \#4 & Capsules (cholesterol reduction) & Globe artichoke, milk thistle & + & + & $\begin{array}{l}22.16 \pm \\
0.19\end{array}$ & 1 & $99.8 \pm 0.2$ \\
\hline \#5 & Capsules (weight loss) & $\begin{array}{l}\text { Globe artichoke powdered leaves, C. scolymus (dried leaf } \\
\text { extract with } 2.5 \% \text { cynarin) }\end{array}$ & + & + & $\begin{array}{l}27.67 \pm \\
0.24\end{array}$ & 1 & $99.4 \pm 0.3$ \\
\hline \#6 & Soluble powder (draining) & Globe artichoke extract $(0.3 \%)$ & + & - & & & \\
\hline \#7 & Soluble powder (draining) & Globe artichoke extract $(0.625 \%)$ & + & - & & & \\
\hline$\# 8$ & Capsules (weight loss) & Globe artichoke extract ( $5 \%$ cynarin) & + & + & $\begin{array}{l}23.68 \pm \\
0.35\end{array}$ & 1 & $99.4 \pm 0.4$ \\
\hline$\# 9$ & Tablets (hepatic detox) & S. marianum (dried extract) & + & - & & & \\
\hline$\# 10$ & Syrup (cholesterol reduction) & C. scolymus (plant) $22 \%, S$. marianum (plant) & + & + & $\begin{array}{l}31.36 \pm \\
1.29\end{array}$ & 4 & $99.2 \pm 0.6$ \\
\hline \#11 & Syrup (weight loss) & C. scolymus (leaves) $0.5 \%$ & + & - & & & \\
\hline \#12 & Ampoules (detox) & C. scolymus (leaves) $1.17 \%$ & + & - & & & \\
\hline \#13 & Ampoules (weight loss) & C. scolymus (leaves) $10 \%$ & - & - & & & \\
\hline \#14 & Ampoules (hepatic detox) & C. scolymus (dry leaf extract) & - & - & & & \\
\hline \#15 & Syrup (draining, satiating) & C. scolymus (leaves) & + & - & & & \\
\hline \#16 & Syrup (antioxidant) & C. scolymus (leaves) $0.1 \%$, S. marianum (leaves) $0.4 \%$ & + & - & & & \\
\hline \#17 & Syrup (draining) & C. scolymus (fluid extract) & + & - & & & \\
\hline \#18 & $\begin{array}{l}\text { Mixed herb infusion (cholesterol } \\
\text { reduction) }\end{array}$ & C. scolymus & + & + & $\begin{array}{l}27.27 \pm \\
0.06\end{array}$ & 1 & $99.6 \pm 0.3$ \\
\hline \#19 & $\begin{array}{l}\text { Mixed herb infusion } \\
\text { (cardioprotection) }\end{array}$ & C. scolymus $(20 \%)$ & + & + & $\begin{array}{l}29.54 \pm \\
0.30\end{array}$ & 1 & $98.2 \pm 1.0$ \\
\hline \#20 & Artichoke \& dandelion infusion & C. scolymus $(20 \%)$ & + & + & $\begin{array}{l}32.06 \pm \\
2.5\end{array}$ & 4 & $99.0 \pm 0.8$ \\
\hline \#21 & $\begin{array}{l}\text { Mixed herb infusion (fat } \\
\text { reduction) }\end{array}$ & C. scolymus $(10 \%)$ & + & - & & & \\
\hline \#22 & Mixed herb infusion & Globe artichoke (10\%) & + & + & $\begin{array}{l}26.37 \pm \\
0.14\end{array}$ & 1 & $98.4 \pm 0.7$ \\
\hline \#23 & Mixed herb infusion (Detox) & Globe artichoke (10\%) & + & + & $\begin{array}{l}29.04 \pm \\
0.02\end{array}$ & 1 & $99.4 \pm 0.7$ \\
\hline \#24 & $\begin{array}{l}\text { Mixed herb infusion } \\
\text { (Hepatoprotection) }\end{array}$ & C. scolymus (20\%), S. marianum (20\%) & + & + & $\begin{array}{l}24.68 \pm \\
0.29\end{array}$ & 1 & $98.8 \pm 0.5$ \\
\hline \#25 & Artichoke infusion & C. scolymus $(100 \%)$ & + & + & $\begin{array}{l}24.72 \pm \\
0.67\end{array}$ & 1 & $98.8 \pm 0.1$ \\
\hline \#26 & $\begin{array}{l}\text { Mixed herb infusion } \\
\text { (Hepatoprotection) }\end{array}$ & C. scolymus & + & + & $\begin{array}{l}24.66 \pm \\
0.14\end{array}$ & 1 & $99.7 \pm 0.3$ \\
\hline \#27 & $\begin{array}{l}\text { Mixed herb infusion (cholesterol } \\
\text { reduction) }\end{array}$ & C. scolymus $(30 \%)$ & + & + & $\begin{array}{l}24.92 \pm \\
0.10\end{array}$ & 1 & $99.1 \pm 0.5$ \\
\hline \#28 & Mixed herb infusion & C. scolymus & + & + & $\begin{array}{l}24.84 \pm \\
0.11\end{array}$ & 4 & $98.2 \pm 0.5$ \\
\hline \#29 & $\begin{array}{l}\text { Mixed herb infusion (weight } \\
\text { loss) }\end{array}$ & C. scolymus $(9.33 \%)$ & + & - & & & \\
\hline
\end{tabular}

${ }^{\mathrm{a}} \mathrm{Cq}$, cycle quantification; ${ }^{\mathrm{b}}$ mean values \pm standard deviation of $n=4$ replicates. 
species, namely Cynara humilis, C. cardunculus and C. syriaca. For this purpose, a method based on real-time PCR coupled to HRM analysis with EvaGreen dye, targeting a marker sequence on the clone CELMS-57 microsatellite, was proposed. Furthermore, the developed approach was applied to authenticate several artichoke-containing foods, including PFS and herbal infusions.

\section{Methods and materials}

\subsection{Plant material and sampling}

Voucher seeds of $C$. scolymus L. were gently provided by the Jardim Botânico de Coimbra (Coimbra, Portugal) and the Universidade de Lisboa (Lisboa, Portugal). Real Jardin Botánico Juan Carlos (Madrid, Spain) kindly provided authentic seeds of $C$. cardunculus L. and C. humilis L., while $C$. syriaca Boiss. seeds were provided by Royal Botanic Garden (Ardingly, West Sussex, UK) (Table S1, Supplementary material). For cross-reactivity assays, 36 plant species were provided by National and International Germplasm Banks or acquired at specialised herbal stores (Table S1, Supplementary material). A total of 9 samples of solid PFS (\#1 - \#9), 8 liquid PFS (\#10 - \#17) and 12 samples of herbal infusions (\#18 - \#29) were acquired at the local market, including specialised herbal stores (Table 1 ).

Seeds were ground with mortar and pestle, while herbal infusions and medicinal plants, mostly consisting of leaf material, were ground, and homogenised separately in a laboratory knife mill Grindomix GM200 (Retsch, Haan, Germany). All materials used during this procedure were previously decontaminated.

\subsection{DNA extraction}

\subsubsection{Seeds}

To extract DNA from seeds, the Nucleospin Plant II kit (MachereyNagel, Düren, Germany) was used according to the manufacturer's instructions, using the PL2 buffer with slight modifications (protocol 2), as described by Costa et al. (2016).

\subsubsection{Leaf material}

The CTAB-PVP method and protocol 2 of the Nucleospin Plant II kit (Macherey-Nagel, Düren, Germany) were used to extract DNA from leaves of medicinal plants and other species used in the cross-reactivity assays (Table S1, Supplementary material) and samples of herbal infusions, as described by Costa et al. (2015) and Costa et al. (2016), respectively, using an initial amount of $100 \mathrm{mg}$ of ground leaf material.

\subsubsection{Plant food supplements}

For DNA extraction of the solid PFS (capsules and powders), both protocols of the Nucleospin Plant II kit (Macherey-Nagel, Düren, Germany) were tested. Prior to the DNA extraction of the solid PFS with protocol 1, a pre-treatment with phosphate buffer $1 \mathrm{M}(\mathrm{pH} 8.0,15 \%$ ethanol) was initially performed. Briefly, $400 \mu \mathrm{L}$ of this buffer were added to $100 \mathrm{mg}$ of each material, mixing vigorously by vortex, and then incubated at $65^{\circ} \mathrm{C}$ with stirring at $700 \mathrm{rpm}$, for $20 \mathrm{~min}$ in a thermomixer (Thermomixer comfort, Eppendorf AG, Hamburg, Germany). After the addition of the PL1 buffer (containing CTAB), the protocol followed the manufacturer's instructions, without the addition of RNase.

DNA extraction of solid PFS, using the protocol 2 of Nucleospin Plant II kit, followed the manufacturer's instructions, with slight modifications, as described by Costa et al. (2016), without the addition of RNase. Liquid plant food supplements (syrups and ampoules) were previously pre-treated as described by Kazi, Hussain, Bremner, Slater, and Howard (2013), with slight modifications. Briefly, in a centrifuge tube, $10 \mathrm{~mL}$ of sample and $10 \mathrm{~mL}$ of absolute ethanol were mixed by vortex and then incubated at room temperature with shaking (Compact Shaker KS $15 \mathrm{~A}$, Edmund Bühler $\mathrm{GmbH}$, Bodelshausen, Germany) for $15 \mathrm{~min}$. The mixture was centrifuged twice at $18,000 \times g\left(10{ }^{\circ} \mathrm{C}\right.$ for $\left.15 \mathrm{~min}\right)$, the supernatant was discarded and the remaining pellet was dried at $50{ }^{\circ} \mathrm{C}$. The dried pellet was transferred to a sterile $2 \mathrm{~mL}$ tube, by the addition of $300 \mu \mathrm{L}$ of ultrapure water, and further extracted using protocol 2 of the Nucleospin Plant II kit as described by Costa et al. (2016), without the addition of RNase.

\subsection{Yield and purity of DNA extracts}

The determinations of yield and purity of DNA extracts were performed by UV spectrophotometry, using a Take3 micro-volume plate accessory, on a Synergy HT multi-mode microplate reader (BioTek Instruments, Inc., Winooski, VT, USA). The nucleic acid protocol was set for double-strand DNA in the Gen5 data analysis software version 2.01 (BioTek Instruments, Inc., Winooski, VT, USA) to determine the DNA content and purity of each extract. The purity of the extracted DNA was determined by the ratio of the absorbance at 260 and $280 \mathrm{~nm}\left(\mathrm{~A}_{260} /\right.$ $\mathrm{A}_{280}$ ).

\subsection{Target gene selection and oligonucleotide primers}

In this work, new primers were specifically designed targeting Cynara spp., using the nucleotide sequence of the clone CELMS-57 microsatellite of $C$. cardunculus (accession number EU744973.1) available at the NCBI database (http://www.ncbi.nlm.nih.gov/). Two primer sets were designed: CyC-F1 (5'-TCCTCTGTGTGGGAAAGTGGCAT-3') and CyC-R1 (5'-TCGCATCTGCCTCTAGTTATAACAGC- ${ }^{\prime}$ ), allowing the production of a fragment with $130 \mathrm{bp}$ of length, which is suitable for HRM analysis; and CyC-FS (5'-TGGACTAAGAGACTGGTCGAGAG-3') and CyC-RS (5'GCCAGAGCAGCCTAGGGTAAATA-3') to amplify larger fragments (373 bp) intended for sequencing analysis. The software Primer3 Output designing tool (http://primer3.ut.ee/) was used to obtain the sequence of the primers, whose properties and the absence of hairpins and selfhybridization were assessed using the software OligoCalc (http://www. basic.northwestern.edu./biotools/ oligocalc.html). The specificity of the primers was assessed using the Primer-BLAST tool (http://www.ncbi. nlm.nih.gov/tools/primer-blast/), allowing revealing potential homologies among all sequences available in the NCBI database. To assess the amplifiability of the DNA extracts, two sets of universal primers (18SRGF/18SRG-R - 113-bp amplicons, and EG-F/EG-R - 113-bp amplicons) targeting a highly conserved $18 \mathrm{~S}$ rRNA region were used (Costa, Oliveira, \& Mafra, 2013; Villa, Costa, Oliveira, \& Mafra, 2017). Primers were synthesised by Eurofins Genomics (Ebersberg, Germany).

\subsection{End-point PCR}

The PCR amplifications were performed in a thermal cycler MJ Mini ${ }^{\text {TM }}$ Gradient Thermal Cycler (Bio-Rad Laboratories, Hercules, CA, USA) and carried out in a total reaction volume of $25 \mu \mathrm{L}$, containing $2 \mu \mathrm{L}$ of DNA extract $(10 \mathrm{ng})$, buffer (67 mM Tris-HCl, pH 8.8, $16 \mathrm{mM}$ $\left(\mathrm{NH}_{4}\right)_{2} \mathrm{SO}_{4}, 0.01 \%$ Tween 20 ), $3.0 \mathrm{mM}$ of $\mathrm{MgCl}_{2}, 1.0 \mathrm{U}$ of SuperHot Taq DNA Polymerase (Genaxxon Bioscience GmbH, Ulm, Germany), $200 \mu \mathrm{M}$ of each dNTP (Grisp, Porto, Portugal) and $280 \mathrm{nM}$ of each primer. The temperature program for primers CyC-F1/CyC-R1 was as follows: (i) initial denaturation at $95{ }^{\circ} \mathrm{C}$ for $5 \mathrm{~min}$; (ii) 40 cycles at $95{ }^{\circ} \mathrm{C}$ for $30 \mathrm{~s}$, $57{ }^{\circ} \mathrm{C}$ for $30 \mathrm{~s}$ and $72{ }^{\circ} \mathrm{C}$ for $30 \mathrm{~s}$; (iii) and a final extension at $72{ }^{\circ} \mathrm{C}$ for 5 min. For primers CyC-FS/ CyC-R, the temperature program was set as follows: (i) initial denaturation at $95{ }^{\circ} \mathrm{C}$ for $5 \mathrm{~min}$; (ii) 40 cycles at $95{ }^{\circ} \mathrm{C}$ for $30 \mathrm{~s}, 56{ }^{\circ} \mathrm{C}$ for $45 \mathrm{~s}$ and $72{ }^{\circ} \mathrm{C}$ for $60 \mathrm{~s}$; (iii) and a final extension at $72{ }^{\circ} \mathrm{C}$ for $5 \mathrm{~min}$. The reactions with primers 18SRG-F/18SRG-R and EGF/EG-R were performed as described by Costa et al. (2013) and Villa et al. (2017), respectively.

The amplified fragments were analysed by electrophoresis in a $1.5 \%$ agarose gel stained with $1 \times$ GelRed (Biotium, Inc., Hayward, CA, USA) and carried out in $1 \times$ SGTB (Grisp, Porto, Portugal) for $25 \mathrm{~min}$ at $200 \mathrm{~V}$. The agarose gel was visualised under a UV light tray Gel Doc ${ }^{\mathrm{TM}} \mathrm{EZ}$ System (Bio-Rad Laboratories, Hercules, CA, USA) and a digital image 
was recorded using Image Lab software version 5.2.1 (Bio-Rad Laboratories, Hercules, CA, USA).

\subsection{Real-time PCR coupled to HRM analysis}

The real-time PCR assays carried out in a total reactional mixture of $20 \mu \mathrm{L}$, containing $20 \mathrm{ng}$ of DNA, $1 \times$ of SsoFast ${ }^{\circledR}$ Evagreen ${ }^{\circledR}$ Supermix (Bio-Rad Laboratories, Hercules, CA, USA) and $400 \mathrm{nM}$ of each primer (CyC-F1/CyC-R1). The reactions were performed in a fluorometric thermal cycler CFX96 Real-time PCR Detection System (Bio-Rad, Hercules, CA, USA), following the temperature conditions: $95^{\circ} \mathrm{C}$ for $5 \mathrm{~min}$; 45 cycles at $95{ }^{\circ} \mathrm{C}$ for $10 \mathrm{~s}, 57{ }^{\circ} \mathrm{C}$ for $20 \mathrm{~s}$ and $72{ }^{\circ} \mathrm{C}$ for $30 \mathrm{~s}$, with a collection of fluorescence signal at the end of each cycle. Data were processed using the software Bio-Rad CFX Manager 3.1 (Bio-Rad Laboratories, Hercules, CA, USA). Real-time PCR trials were done in four replicates for each sample.

For HRM analysis, PCR products were denatured at $95{ }^{\circ} \mathrm{C}$ for $1 \mathrm{~min}$ and held at $65{ }^{\circ} \mathrm{C}$ for $5 \mathrm{~min}$, allowing the correct annealing of the DNA duplexes, followed by melting curve ranging from $65{ }^{\circ} \mathrm{C}$ to $95{ }^{\circ} \mathrm{C}$ with temperature increments of $0.2{ }^{\circ} \mathrm{C}$ every $10 \mathrm{~s}$. Fluorescence data were acquired at the end of each melting phase and processed using the Precision Melt Analysis Software 1.3 (Bio-Rad Laboratories, Hercules, CA, USA) to generate melting curves, as a function of temperature, and difference curves for easy visual identification of clusters. Melting curve shape sensitivity determines the stringency used to classify into different clusters, while the temperature of melting (Tm) difference threshold defines the lowest Tm difference among samples. Cluster detection parameters were set to high sensitivity and threshold yields, to provide more heterozygote clusters (Bio-Rad, 2012). The HRM results were analysed by adjusting the melting curve shape sensitivity to a percentage value of $50 \%$ and setting the Tm difference threshold parameter as a default value of 0.2 .

\subsection{Sequencing of purified PCR products}

The primers CyC-FS/CyC-RS, producing 373-bp amplicons to cover the region amplified by the primers CyC-F1/CyC-R1, were used for sequencing the four reference species: C. scolymus L., C. cardunculus L., C. humilis L. and C. syriaca Boiss. After PCR amplification, the products were purified with the kit GRS PCR \& Gel Band Purification Kit (GRISP, Porto, Portugal), to remove any possible interfering components and further sent to a specialised research facility (Eurofins Genomics, Ebersberg, Germany). Each target fragment was sequenced twice, performing direct sequencing of both strands in opposite directions, which allowed the production of two complementary sequences with good quality. The sequencing data were analysed by the software FinchTV (Geospiza, Seattle, WA, USA) and aligned by BioEdit v7.2.5 (Ibis Biosciences, Carlsbad, CA, USA).

\section{Results and discussion}

\subsection{Quality of DNA extracts}

Generally, DNA extracts from plant materials, namely seeds, leaves and herbal infusions, showed sufficient or high DNA yields, within 36.7-321.5 ng/ $\mu \mathrm{L}, 5.9-1022.2 \mathrm{ng} / \mu \mathrm{L}$ and 33.8-281.1 $\mathrm{ng} / \mu \mathrm{L}$, respectively, with purities $\left(\mathrm{A}_{260} / \mathrm{A}_{280}\right)$ ranging from 1.7 to 2.2 , which provided amplifiable DNA targeting a eukaryotic region (Table $S 1$, supplementary material and Table 1).

Regarding the PFS, the DNA yields were mostly lower, being within 10.5-167.0 ng/ $\mu \mathrm{L}$ for most solid samples (\#1, \#2, \#4, \#5 and \#8) and $7.0 \mathrm{ng} / \mu \mathrm{L}$ for one liquid sample (\#10) or not quantifiable (below UV/Vis spectrophotometric detection) for the remaining samples (\#3, \#6, \#7, \#9, \#11-17) (Table 1). To overcome difficulties in extracting DNA from PFS, two approaches were used for the solid samples, based on the two protocols of the Nucleospin Plant kit, applying a phosphate buffer pre- treatment before protocol 1 (section 2.2.3). According to Direito, Marees, and Röling (2012), such buffer promotes a chemical competition with DNA by the silica adsorption locations, allowing to increase the recovery rates of DNA extraction of nucleic acids from bacteria and fungi, adsorbed on earth and mars minerals. Comparing DNA extraction of solid PFS with both methods, it can be verified that protocol 2 provided slightly higher yields $(14.8-167.0 \mathrm{ng} / \mu \mathrm{L})$ than the protocol 1 with the phosphate buffer pre-treatment (10.5-106.4 ng/ $\mu \mathrm{L})$. However, the later provided a general increased amplification capacity, when observing the band intensity of PCR targeting the universal eukaryotic region (18S rRNA gene), meaning that the pre-treatment of the solid samples, before DNA extraction, effectively improved the quality of DNA extracts from solid PFS, which were all amplified (Table 1). Despite the low DNA yields of liquid PFS due to their high level of processing, most of them were successfully amplified targeting the universal eukaryotic region, with the exceptions of samples \#13 and \#14 (Table 1).

\subsection{Cynara-specific PCR assay}

In this work, the sequence of the clone CELMS-57 microsatellite of C. cardunculus was selected for the development of a PCR assay targeting Cynara spp. All extracts of Cynara genus voucher seeds were successfully amplified, presenting the expected PCR products of $130 \mathrm{bp}$ with primers CyC-F1/CyC-R1 (Table S1, supplementary material). The primer specificity was verified in silico and further confirmed experimentally by PCR using other 36 plant species, mostly medicinal plants. The results showed no amplification with all tested plant species, except for Silybum marianum that presented a faint band (Table S1, Fig. S1, supplementary material), confirming the high specificity level of the assay for Cynara spp.

The PCR results of solid PFS showed that only samples \#4, \#5 and \#8 were amplified for the Cynara spp., while in the liquid PFS, only one sample was positive (Table 1). The positive PFS samples were obtained from extracts with relatively high DNA yields (59.4-167.0 ng/ $\mathrm{LL}$ ), using the PL2 buffer of Nucleospin Plant II. Despite the higher amplification capacity (targeting the 18S rRNA gene) obtained with the PL1 buffer of the NucleoSpin Plant II kit with a phosphate buffer pre-treatment, the Cynara-specific PCR assay provided the best results for both types of PFS (solid and liquid) using the PL2 buffer of the same kit, without any pretreatment. In opposition, the negative results were all from the lowest DNA yield extracts $(<20 \mathrm{ng} / \mu \mathrm{L}$ or not detected).

Therefore, these findings should be attributed to the poor DNA yields, together with the loss of DNA integrity due to processing, or simply due the absence or very low amount of globe artichoke. In the case of herbal infusion samples, Cynara-specific PCR was positive for 10 out of 12 samples (Table 1), which suggests a possible mislabelling in samples \#21 and \#29.

\subsection{Real-time PCR amplification coupled to HRM analysis}

\subsubsection{Method development}

Following the successful proposal of a Cynara-specific PCR assay, a real-time PCR method with EvaGreen dye and HRM analysis was developed using the newly designed primers (CyC-F1/CyC-R1). For this purpose, a 10 -fold serially dilution of a C. scolymus DNA extract ( $40 \mathrm{ng}$ to $0.4 \mathrm{pg}$ ) was prepared to cover 6 concentration levels. The amplification and respective melting curves are presented in Fig. $1 \mathrm{~A}$ and $1 \mathrm{~B}$, respectively. The conventional melting curve analysis shows similar profiles with melt peaks at $79.27 \pm 0.15^{\circ} \mathrm{C}$, which confirms the absence of nonspecific amplicons (Fig. 1B). Fig. 1C presents the obtained real-time PCR calibration curve, covering the levels of $40 \mathrm{ng}$ to $0.4 \mathrm{pg}$ of $C$. scolymus DNA. The acceptance criteria for real-time PCR assays were established according to Bustin et al. (2009) and ENGL (2015), which considered the slope within -3.6 and -3.1 , the PCR efficiency between 90 and $110 \%$ and the correlation coefficient $\left(R^{2}\right) \geq 0.98$. Accordingly, data shows that such criteria were fulfilled, with a PCR efficiency of $105.2 \%$, a $R^{2}$ of 
A

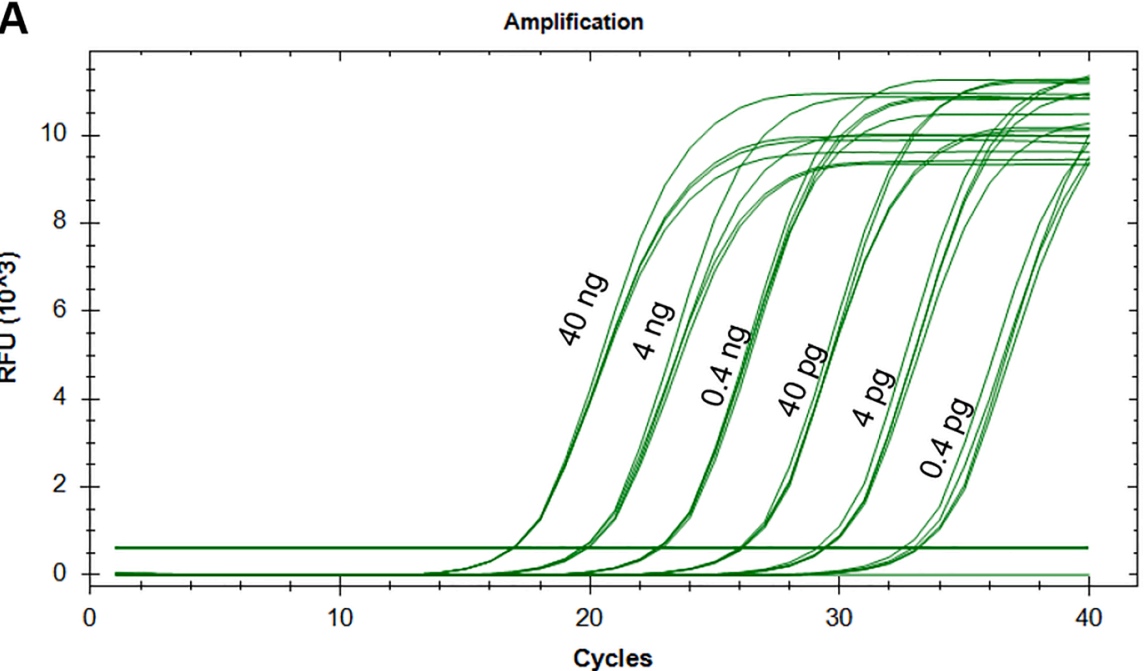

B

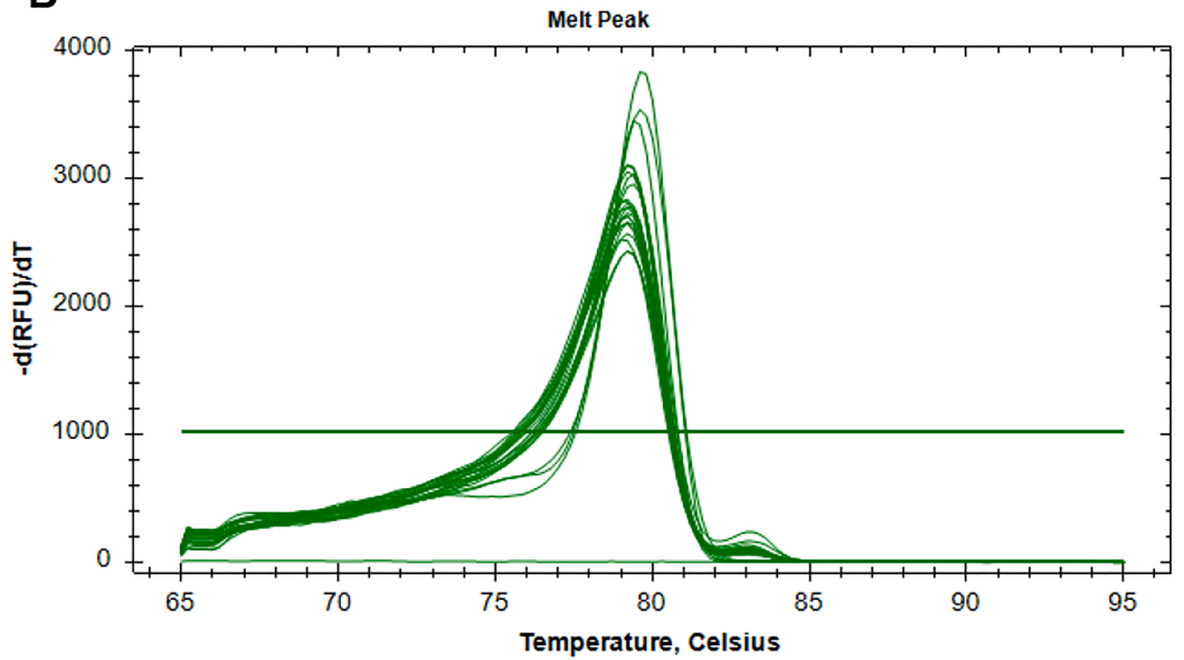

C

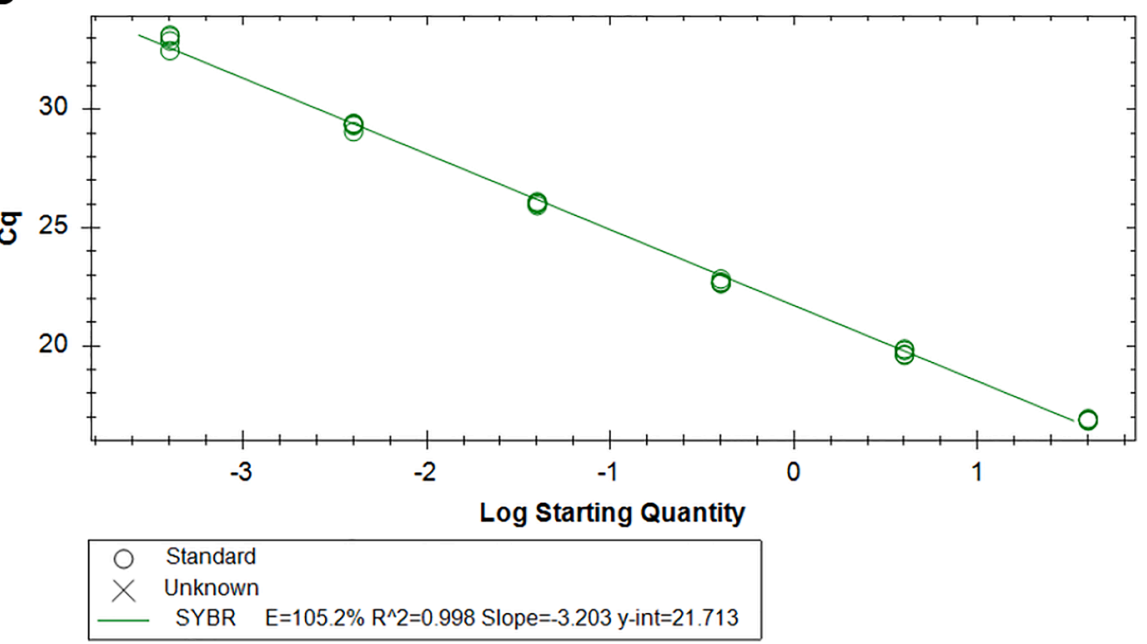

Fig. 1. Amplification (A), melting (B) and calibration (C) curves of a real-time PCR assay with EvaGreen dye, targeting the region Clone CELMS-57 microsatellite sequence of $C$. cardunculus. The amplified extracts were obtained from 10-fold serially diluted $C$. scolymus DNA from $40 \mathrm{ng}$ to $0.4 \mathrm{pg}(n=4 \mathrm{replicates})$.

0.998 and a slope of -3.203 (Fig. 1C). The limit of detection (LOD) was established as the lowest amplified level for $95 \%$ of the replicates and the limit of quantification (LOQ) as the lowest amplified level within the linear dynamic range of the calibration curve that should cover at least 4 orders of magnitude (Bustin et al., 2009; ENGL, 2015). Hence, the amplification of all replicates $(n=4)$ allowed establishing an absolute LOD of $0.4 \mathrm{pg}(\mathrm{Cq}=32.23 \pm 0.26)$ of $C$. scolymus DNA (Fig. 1C), which was also considered as the LOQ because it was within the linear dynamic 
range of the calibration curve, covering 6 orders of magnitude. Considering the available $C$. scolymus genome size (1.11 pg) (Plant DNA C-values database, RBG, Kew, UK, https://cvalues.science.kew. org/search) and assuming that the targeted sequences are single-copy genes, the LOD of $0.4 \mathrm{pg}$ corresponds to 0.36 DNA copies.

The real-time PCR assay coupled to HRM analysis was then applied to discriminate the four Cynara species under study: C. scolymus, C. cardunculus, C. humilis and C. syriaca. The four species were amplified with Cq values ranging from 17.35 to 19.37 (Table 2). The results of the conventional melting curve analysis showed close melt peaks between 79.3 and $79.5^{\circ} \mathrm{C}$ for all the species (Fig. 2A, Table 2). This fact suggests that PCR amplicons have very similar nucleotide composition and size, which does not allow their differentiation based on this analysis (Fig. 2A). Therefore, HRM analysis was applied as an approach to differentiate amplicons with small nucleotide variations. Fig. $2 \mathrm{~B}$ and $2 \mathrm{C}$ present the obtained normalised and difference curves for the four Cynara species, showing their discrimination into three independent clusters with high levels of confidence ( $>99.3 \%)$ : C. scolymus as cluster 1 (reference cluster); C. cardunculus and C. humilis, both included in cluster 2; and C. syriaca as cluster 3 (Table 2). Therefore, these results show that HRM analysis can differentiate globe artichoke (C. scolymus) from the other closely related species. In fact, depending on the authors, C. scolymus, C. cardunculus and C. syriaca might be considered botanical varieties of the same species (Ancora, 1986; IPNI, 2021). Besides, the wild taxon of $C$. cardunculus [var. sylvestris (Lamk) Fiori] has been recognised as the ancestor of both globe artichoke [var. sativa Moris, var. scolymus (L.) Fiori, subsp. scolymus (L.) Hegi] and the leafy or cultivated cardoon (var. altilis DC) (Sonnante, Pignone, \& Hammer, 2007). Accordingly, these findings together with the obtained results highlight the potential of HRM analysis in differentiating genetically related taxa.

To further verify the specificity of the primers that previously amplified Sylibum marianum by end-point PCR (Fig. S1, supplementary material), the proposed real-time PCR method with HRM analysis was assayed for this species owing to its common use in mixed plant food supplements and infusions. The results show that $S$. marianum was amplified, but at delayed quantification cycles $(\mathrm{Cq}=33.26 \pm 0.15)$, comparing with $C$. scolymus $(\mathrm{Cq}=19.73 \pm 0.13)$, using the same amount of template DNA (4 ng) (Fig. S2A, supplementary material). The melting curve profiles were distinct for both species, as noted in the obtained melt peaks (Fig. S2B, supplementary material) and respective difference curves (Fig. S2C, supplementary material), highlighting inconsistent and multiple melt peaks for $S$. marianum, probably due to poor primer annealing for this species (Fig. S2B, supplementary material). Therefore, the developed HRM method was able to differentiate $C$. scolymus from $S$. marianum, demonstrating the high specificity of this assay for C. scolymus discrimination.

\section{Table 2}

Results of real-time PCR coupled to HRM analysis applied to Cynara reference species.

\begin{tabular}{|c|c|c|c|c|}
\hline \multirow[t]{2}{*}{ Species } & \multirow{2}{*}{$\begin{array}{l}\text { Real-time } \\
\text { PCR } \\
\text { Cq values }^{\mathrm{a}, \mathrm{b}}\end{array}$} & \multirow[b]{2}{*}{$\operatorname{Tm}\left({ }^{\circ} \mathrm{C}\right)^{\mathrm{c}}$} & \multicolumn{2}{|c|}{ HRM analysis } \\
\hline & & & Cluster & $\begin{array}{l}\text { Level of } \\
\text { confidence }\end{array}$ \\
\hline Cynara scolymus L. & $\begin{array}{l}17.35 \pm \\
0.11\end{array}$ & $\begin{array}{l}79.25 \pm \\
0.13\end{array}$ & 1 & $99.6 \pm 0.4$ \\
\hline Cynara humilis L. & $\begin{array}{l}19.32 \pm \\
0.11\end{array}$ & $\begin{array}{l}79.56 \pm \\
0.16\end{array}$ & 2 & $99.4 \pm 0.7$ \\
\hline $\begin{array}{l}\text { Cynara cardunculus } \\
\text { L. }\end{array}$ & $\begin{array}{l}19.37 \pm \\
0.07\end{array}$ & $\begin{array}{l}79.53 \pm \\
0.15\end{array}$ & 2 & $99.6 \pm 0.4$ \\
\hline $\begin{array}{l}\text { Cynara syriaca } \\
\text { Boiss. }\end{array}$ & $\begin{array}{l}17.70 \pm \\
0.07\end{array}$ & $\begin{array}{l}79.31 \pm \\
0.14\end{array}$ & 3 & $99.7 \pm 0.3$ \\
\hline
\end{tabular}

\footnotetext{
a Cq, cycle quantification;

b mean values \pm standard deviation of $n=4$ replicates;

c $\mathrm{Tm}$, temperature of melting.
}

\subsubsection{Application of the method to commercial products}

Following the successful development of the real-time PCR method coupled to HRM analysis to differentiate $C$. scolymus from the other three Cynara species, its applicability to commercial PFS and herbal infusions was further demonstrated. The real-time PCR amplification results were in good agreement with end-point PCR, confirming the presence of Cynara spp. (Table 1). The results of HRM analysis showed that most samples of PFS and herbal infusions (Fig. 3), confirmed as containing Cynara spp., were grouped in cluster 1 (C. scolymus) with a high level of confidence $(>98.2 \%)$ (Table 1$)$. Therefore, these results suggest that most samples complied with the labelled information of containing C. scolymus as an ingredient. The exceptions were the samples \#10, \#20 and \#28 that formed an undefined cluster (4) (Fig. 3D, Table 1), not being grouped with any of the other three Cynara clusters. This finding could be explained by the strong inhibitory effects observed in their amplification profiles. In fact, the three refered samples were amplified at delayed cycles (Cq $<32.23$ (LOD)) with the same melting temperature $\left(79.60^{\circ} \mathrm{C}\right)$ (data not shown), thus suggesting that their identification as Cynara spp.

In summary, the results of method application to PFS showed that it was possible to obtain amplifiable DNA from 15 out of 17 samples. However, the successful rate for the detection of Cynara species was quite lower since it was only identified in 4 PFS. This can be related to the fact that most samples contain plant extracts rather than leaf material, which in addition to excipients and processing, particularly in liquid samples, makes the DNA extraction of the target species a very hard task to accomplish. Besides, the proportion of globe artichoke as an ingredient in mixed plant formulations, such as the PFS, is generally low. Despite the referred issues, it was possible to confirm the presence of C. scolymus in the PFS samples \#4, \#5 and \#8. The absence of Cynara DNA in sample \#9 is according to the labelled information because it declares $S$. marianum, but not C. scolymus. Sample \#10 is included in an undefined cluster, most likely owing to the complexity of the matrix and the presence of inhibitors, thus reflecting a limitation of the developed method in this case. Regarding the 12 samples of herbal infusions (\#18\#29), as expected, they all provided amplifiable DNA, from which C. scolymus was confirmed in 8 samples (cluster 1 ). Although identifying Cynara spp., the two samples (\#20 and \#28) with strong PCR inhibition disabled their correct HRM clustering. The remaining two samples (\#21 and \#29) were negative for C. scolymus, thus not complying with the labelled information (Table 1). It is also important to refer that the presence of $S$. marianum species in sample \#24 did not interfere with the reliability of $C$. scolymus identification, which was obtained with a high level of confidence $(98.8 \pm 0.5)$.

\subsection{Analysis of sequencing data}

The four Cynara species (C. scolymus, C. humilis, C. cardunculus and C. syriaca) used in method development were amplified with primers CyC-FS/CyC-RS to obtain 373-bp fragments, encompassing the target 130-bp HRM amplicons, which are too short for accurate sequencing. Each PCR product was amplified at least in duplicate, followed by direct sequencing of both strands in opposite directions. The obtained electropherograms provided adequate resolution, allowing the sequence alignment of the four Cynara species with the retrieved NCBI sequence (accession no. EU744973.1) (Fig. 4). Contrarily to the expected, the sequence results highlight two mismatches in the annealing region of both primers (CyC-F1/CyC-R1), which were consistent in the four species and found in positions 9 and 22, for the forward primer, and positions 109 and 116, for the reverse primer. However, this occurrence did not compromise the amplification efficiency, particularly when observing real-time PCR performance data in Fig. 1. Comparing sequence data of the four species with the retrieved sequence, within the region of HRM analysis, it can be noted that all species share two 

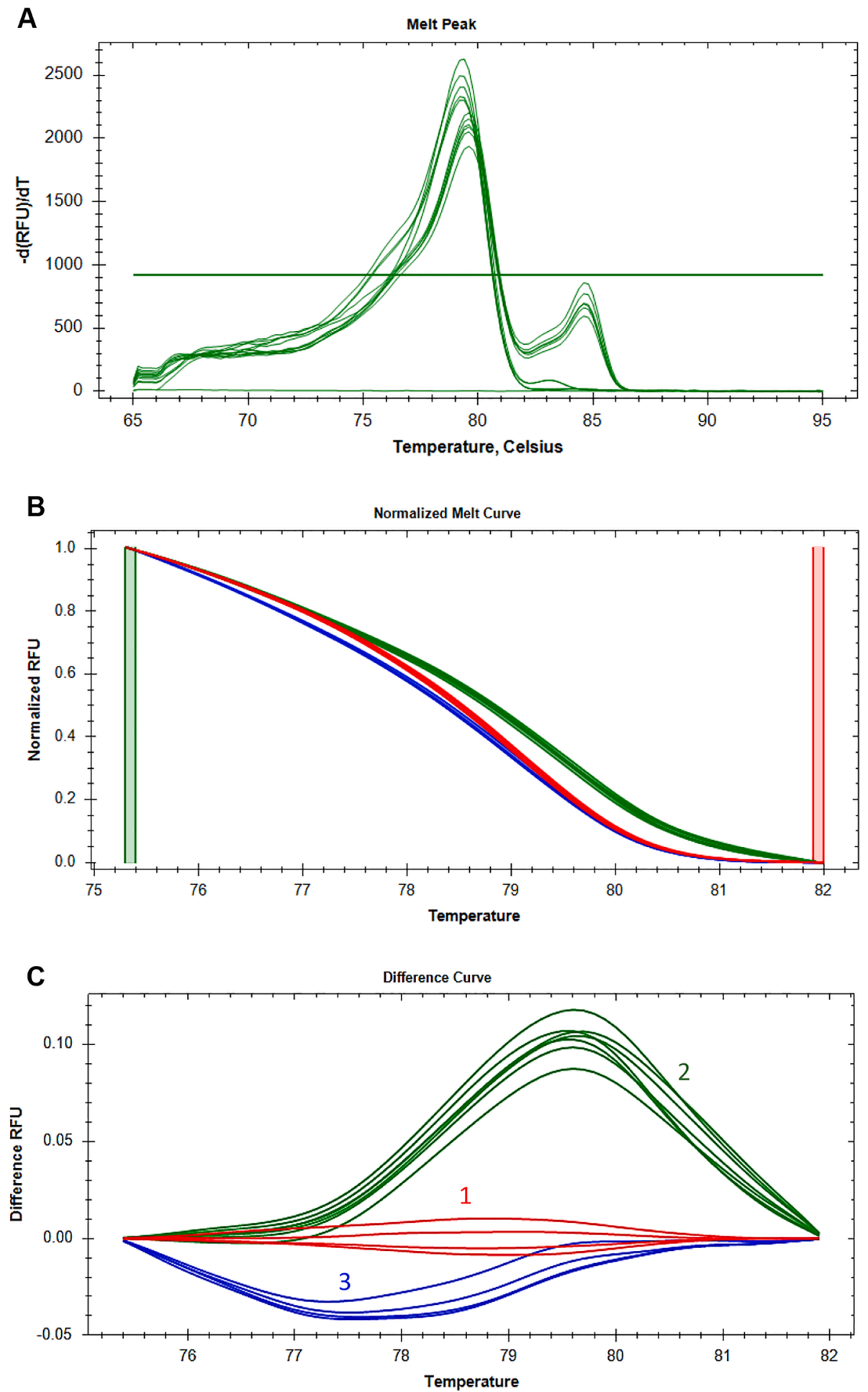

Fig. 2. Conventional melting (A), normalised melting (B) and difference (C) curves obtained by real-time PCR amplification with EvaGreen dye and HRM analysis targeting the CELMS-57 microsatellite sequence of $C$. cardunculus. Legend: 1, C. scolymus (cluster 1); 2, C. cardunculus, C. humilis (cluster 2); 3, C. syriaca (cluster 3) (n $=4$ replicates)

mismatches in the positions 144 and 145 (TT instead CG) and one in the position 187 (A instead of a T). Besides, C. humilis, C. cardunculus and C. syriaca have one nucleotide difference in the position 143 , while C. humilis, C. cardunculus have one undefined nucleotide R (A or G) in the position 203 (Fig. 4). Thus, these findings allow explaining the discrimination of $C$. scolymus from the other Cynara species presented in this study.

\section{Conclusions}

In this work, a novel real-time PCR method coupled to HRM analysis was proposed for the first time to differentiate globe artichoke (C. scolymus) from other Cynara species (C. humilis, C. cardunculus and C. syriaca). For this purpose, new specific primers were designed, demonstrating high specificity for Cynara species. Afterwards, a Cynaraspecific real-time PCR assay was successfully developed with high 
A

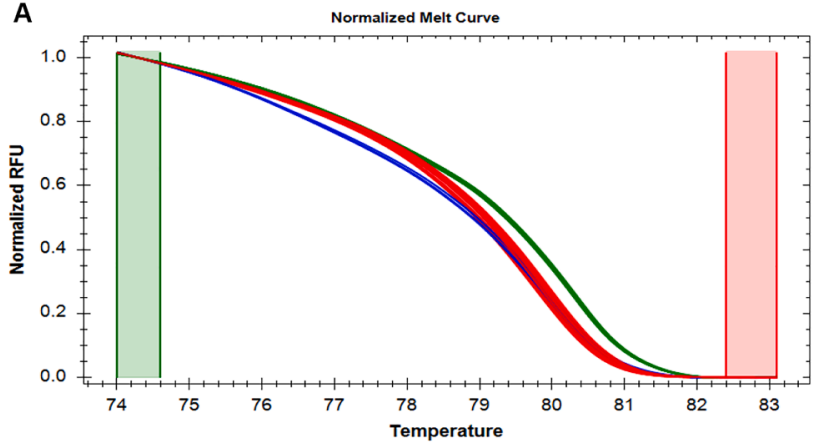

C

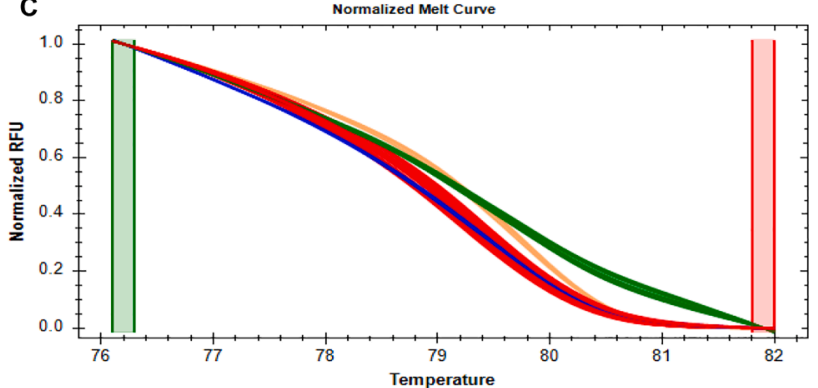

B

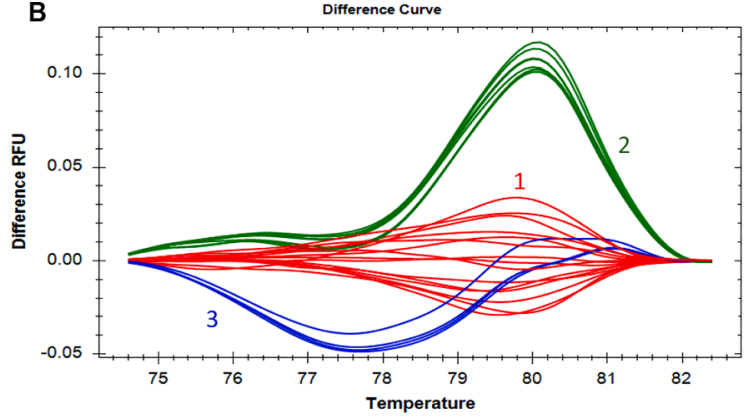

D

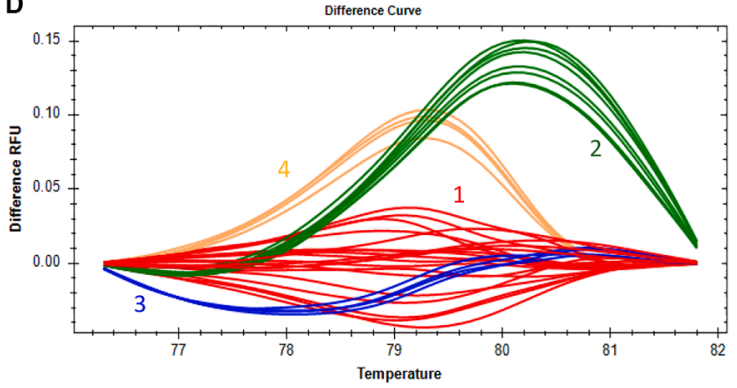

Fig. 3. Normalised melting (A, C) and difference (B, D) curves obtained by real-time PCR amplification with EvaGreen dye and HRM analysis targeting the CELMS-57 microsatellite sequence of C. cardunculus. Legend: 1, C. scolymus, solid plant food supplements (\#4, \#5, \#8) (B), artichoke herbal infusions (\#23, \#24, \#26, \#27) (D); 2, C. cardunculus, C. humilis; 3, C. syriaca; 4, sample \#28 ( $n=4$ replicates).
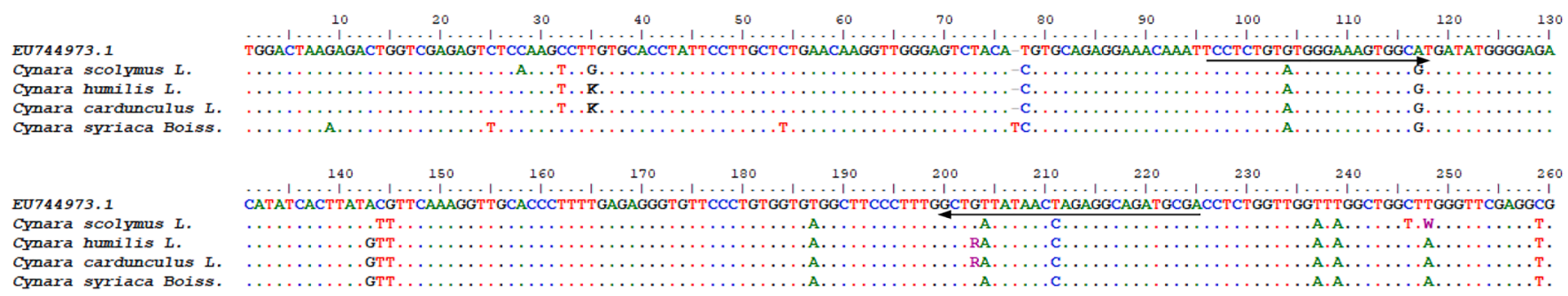

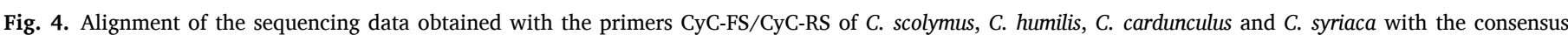

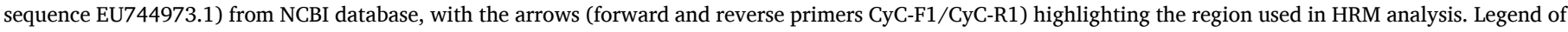
undefined bases: K, represents G or T; R, A or G; W, A or T; Y, C or T.

analytical performance parameters, achieving a sensitivity down to 0.4 pg of globe artichoke DNA (0.36 copies). HRM analysis enabled the discrimination of C. scolymus from other Cynara species, with a high level of confidence ( $>98 \%$ ), which corroborated sequencing data. The method applicability was demonstrated with commercial samples of artichoke-containing PFS and mixed plant herbal infusions, from which a high successful rate of amplifiable DNA was obtained, despite the difficulties in extracting PFS.

In summary, the present study shows that 11 samples were in good agreement with the labelled globe artichoke species, 2 samples did not allow the accurate discrimination of Cynara species, 2 samples suggest the substitution/mislabelling of globe artichoke, while the remaining 13 PFS provide inconclusive results, suggesting the need for further efforts to increase DNA amplifiability. Therefore, the present work provides a new cost-effective tool for the botanical authentication of globe artichoke-containing foods, with full applicability to mixed herbal products, but also to some solid PFS formulations, being potentially useful for control laboratories of such products.

\section{CRediT authorship contribution statement}

Liliana Grazina: Methodology, Formal analysis, Investigation, Writing - original draft. Andreia Batista: Methodology, Formal analysis, Investigation. Joana S. Amaral: Conceptualization, Supervision, Writing - review \& editing. Joana Costa: Formal analysis, Investigation, Writing - review \& editing. Isabel Mafra: Conceptualization, Funding acquisition, Supervision, Writing - review \& editing.

\section{Funding}

The work was funded through the projects UIDB/50006/2020, subsidised by FCT/MCTES (Fundação para a Ciência e Tecnologia and Ministério da Ciência, Tecnologia e Ensino Superior) through national funds and the project NORTE-01-0145-FEDER-000052. L. Grazina thanks FCT and ESF (European Social Fund) through POCH (Programa Operacional Capital Humano) for her PhD grant SFRH/BD/132462/ 2017. J. Costa thanks FCT for funding through program DL 57/2016 Norma transitória (SFRH/BPD/102404/2014).

\section{Declaration of Competing Interest}

The authors declare that they have no known competing financial interests or personal relationships that could have appeared to influence the work reported in this paper. 


\section{Acknowledgments}

The authors are grateful to the University of Lisbon and Jardim Botânico de Coimbra (Portugal), Real Jardin Botánico Juan Carlos (Spain), Seed Conservation Department of Royal Botanic Garden (UK) and Jardin des plantes et Botanique (France) for the supply of plant material. The authors acknowledge the support of the project UIDB 00690/2020, subsidised by FCT/MCTES (Fundação para a Ciência e Tecnologia and Ministério da Ciência, Tecnologia e Ensino Superior) through national funds.

\section{Appendix A. Supplementary data}

Supplementary data to this article can be found online at https://doi. org/10.1016/j.foodchem.2021.130621.

\section{References}

Ancora, G. (1986). Globe artichoke (Cynara scolymus L.). In Y. P. S. Bajaj (Ed.), Crops I Biotechnology in Agriculture and Forestry. Berlin, Heidelberg: Springer.

Bio-Rad (2012). Precision melt analysis software - Instruction manual. https://www bio-rad.com/webroot/web/pdf/Isr/literature/Bulletin 10014811.pdf.

Bustin, S. A., Benes, V., Garson, J. A., Hellemans, J., Huggett, J., Kubista, M. Wittwer, C. T. (2009). The MIQE guidelines: minimum information for publication of quantitative real-time PCR experiments. Clinical Chemistry, 55, 611-622. https://doi org /10.1373/clinchem.2008.112797.

Costa, J., Amaral, J. S., Fernandes, T. J. R., Batista, A., Oliveira, M. B. P. P., \& Mafra, I. (2015). DNA extraction from plant food supplements: Influence of different pharmaceutical excipients. Molecular and Cellular Probes, 29(6), 473-478. https:// doi.org/10.1016/j.mcp.2015.06.002.

Costa, J., Campos, B., Amaral, J. S., Nunes, M. E., Oliveira, M. B. P. P., \& Mafra, I. (2016). HRM analysis targeting ITS1 and matK loci as potential DNA mini-barcodes for the authentication of Hypericum perforatum and Hypericum androsaemum in herbal infusions. Food Control, 61, 105-114. https://doi.org/10.1016/j. foodcont.2015.09.035.

Costa, J., Melo, V. S., Santos, C. G., Oliveira, M. B. P. P., \& Mafra, I. (2015). Tracing tree nut allergens in chocolate: A comparison of DNA extraction protocols. Food Chemistry, 187, 469-476. https://doi.org/10.1016/j.foodchem.2015.04.073.

Costa, J., Oliveira, M. B. P. P., \& Mafra, I. (2013). Effect of thermal processing on the performance of the novel single-tube nested real-time PCR for the detection of walnut allergens in sponge cakes. Food Research International, 54(2), 1722-1729. https://doi.org/10.1016/j.foodres.2013.09.047.

Direito, S. O. L., Marees, A., \& Röling, W. F. M. (2012). Sensitive life detection strategies for low-biomass environments: Optimizing extraction of nucleic acids adsorbing to terrestrial and Mars analogue minerals. FEMS Microbiology Ecology, 81(1), 111-123. https://doi.org/10.1111/j.1574-6941.2012.01325.x.

Druml, B., \& Cichna-Markl, M. (2014). High resolution melting (HRM) analysis of DNA Its role and potential in food analysis. Food Chemistry, 158, 245-254. https://doi. org/10.1016/j.foodchem.2014.02.111.

El Senousy, A. S., Farag, M. A., Al-Mahdy, D. A., \& Wessjohann, L. A. (2014). Developmental changes in leaf phenolics composition from three artichoke cvs. (Cynara scolymus) as determined via UHPLC-MS and chemometrics. Phytochemistry, 108, 67-76. https://doi.org/10.1016/j.phytochem.2014.09.004.

EMA (2018). Assessment report on Cynara cardunculus L. (syn. Cynara scolymus L.), folium. EMA/HMPC/194013/2017. Committee on herbal medicinal products (HMPC). https://www.ema.europa.eu/en/documents/herbal-report/final-assessme nt-report-cynara-cardunculus-1-syn-cynara-scolymus-1-folium_en.pdf.

ENGL (2015). Definition of minimum performance requirements for analytical methods of GMO testing. European network of GMO laboratories, Join Research Centre, EURL. https://gmo-crl.jrc.ec.europa.eu/doc/MPR\%20Report\%20Application\%2020 10_2015.pdf.

Franz, C., Chizzola, R., Novak, J., \& Sponza, S. (2011). Botanical species being used for manufacturing plant food supplements (PFS) and related products in the EU member states and selected third countries. Food \& Function, 2, 720-730. https://doi.org/ 10.1039/C1FO10130G.

Garcia-Alvarez, A., Mila-Villarroel, R., Ribas-Barba, L., Egan, B., Badea, M., Maggi, F. M., Serra-Majem, L. (2016). Usage of plant food supplements (PFS) for weight control in six European countries: Results from the PlantLIBRA PFS Consumer Survey 2011-2012. BMC Complementary and Alternative Medicine, 16(1). https://doi.org/ 10.1186/s12906-016-1227-5.

Grazina, L., Amaral, J. S., Costa, J., \& Mafra, I. (2020). Authentication of Ginkgo biloba herbal products by a novel quantitative real-time PCR approach. Foods, 9, 1233. https://doi.org/10.3390/foods9091233.
Grazina, L., Amaral, J. S., \& Mafra, I. (2020). Botanical origin authentication of dietary supplements by DNA-based approaches. Comprehensive Reviews in Food Science and Food Safety, 19(3), 1080-1109. https://doi.org/10.1111/crf3.v19.310.1111/15414337.12551.

Grazina, L., Costa, J., Amaral, J. S., \& Mafra, I. (2021). High-resolution melting analysis as a tool for plant species authentication. In P. Tripodi (Ed.), Crop Breeding: Genetic Improvement Methods (pp. 55-73). New York, NY: Springer, US.

Heubl, G. (2010). New aspects of DNA-based authentication of Chinese medicinal plants by molecular biological techniques. Planta Medica, 76(17), 1963-1974. https://doi. org/10.1055/s-0030-1250519.

Howard, C., Lockie-Williams, C., \& Slater, A. (2020). Applied barcoding: The practicalities of DNA testing for herbals. Plants, 9, 1150. https://doi.org/10.3390/ plants9091150.

IPNI (2021). International Plant Name Index (IPNI). The Royal Botanic Gardens, Kew, Harvard University Herbaria \& Libraries and Australian National Botanic Gardens. Retrieved from: https://www.ipni.org/. Accessed April, 302021.

Jung, J., Kim, K. H., Yang, K., Bang, K.-H., \& Yang, T.-J. (2014). Practical application of DNA markers for high-throughput authentication of Panax ginseng and Panax quinquefolius from commercial ginseng products. Journal of Ginseng Research, 38(2), 123-129. https://doi.org/10.1016/j.jgr.2013.11.017.

Kazi, T., Hussain, N., Bremner, P., Slater, A., \& Howard, C. (2013). The application of a DNA-based identification technique to over-the-counter herbal medicines. Fitoterapia, 87, 27-30. https://doi.org/10.1016/j.fitote.2013.03.001.

Li, J., Xiong, C., He, X., Lu, Z., Zhang, X., Chen, X., \& Sun, W. (2018). Using SSR-HRM to identify closely related species in herbal medicine products: A case study on Licorice. Frontiers in Pharmacology, 9, 407. https://doi.org/10.3389/fphar.2018.00407.

Mishra, P., Shukla, A. K., \& Sundaresan, V. (2018). Candidate DNA barcode tags combined with high resolution melting (Bar-HRM) curve analysis for authentication of Senna alexandrina Mill. with validation in crude drugs. Frontiers Plant Science, 9. https://doi.org/10.3389/fpls.2018.00283.

Morris, C., \& Morris, G. A. (2012). The effect of inulin and fructo-oligosaccharide supplementation on the textural, rheological and sensory properties of bread and their role in weight management: A review. Food Chemistry, 133(2), 237-248. https://doi.org/10.1016/j.foodchem.2012.01.027.

Osathanunkul, M., \& Madesis, P. (2019). Bar-HRM: a reliable and fast method for species identification of ginseng (Panax ginseng, Panax notoginseng, Talinum paniculatum and Phytolacca Americana). Peerj, 7(17). https://doi.org/10.7717/peerj.7660.

Osathanunkul, M., Osathanunkul, R., \& Madesis, P. (2018). Species identification approach for both raw materials and end products of herbal supplements from Tinospora species. BMC Complementary and Alternative Medicine, 18, 111. https://doi. org/10.1186/s12906-018-2174-0.

Pereira, C., Barros, L., \& Ferreira, I. C. F. R. (2014). Analytical tools used to distinguish chemical profiles of plants widely consumed as infusions and dietary supplements: Artichoke, milk thistle, and borututu. Food Analytical Methods, 7(8), 1604-1611. https://doi.org/10.1007/s12161-014-9795-9.

Ruiz-Cano, D., Pérez-Llamas, F., Frutos, M. J., Arnao, M. B., Espinosa, C., LópezJiménez, J.Á., ... Zamora, S. (2014). Chemical and functional properties of the different by-products of artichoke (Cynara scolymus L.) from industrial canning processing. Food Chemistry, 160, 134-140. https://doi.org/10.1016/j foodchem.2014.03.091.

Song, M., Li, J., Xiong, C., Liu, H., \& Liang, J. (2016). Applying high-resolution melting (HRM) technology to identify five commonly used Artemisia species. Scientific Reports, 6, 34133. https://doi.org/10.1038/srep34133.

Sonnante, G., Pignone, D., \& Hammer, K. (2007). The domestication of artichoke and cardoon: From Roman times to the genomic age. Annals of Botany, 100, 1095-1100. https://doi.org/10.1093/aob/mcm127.

Sun, W., Li, J.-J., Xiong, C., Zhao, B., \& Chen, S.-L. (2016). The potential power of BarHRM technology in herbal medicine identification. Frontiers in Plant Science, 7, 367. https://doi.org/10.3389/fpls.2016.00367.

Turkiewicz, I. P., Wojdyło, A., Tkacz, K., Nowicka, P., \& Hernández, F. (2019). Antidiabetic, anticholinesterase and antioxidant activity vs. terpenoids and phenolic compounds in selected new cultivars and hybrids of artichoke Cynara scolymus L. Molecules, 24, 1222. https://doi.org/10.3390/molecules24071222.

Veldman, S., Ju, Y., Otieno, J. N., Abihudi, S., Posthouwer, C., Gravendeel, B., ... de Boer, H. J. (2020). DNA barcoding augments conventional methods for identification of medicinal plant species traded at Tanzanian markets. Journal of Ethnopharmacology, 250, 112495. https://doi.org/10.1016/j.jep.2019.112495.

Villa, C., Costa, J., Oliveira, M. B. P. P., \& Mafra, I. (2017). Novel quantitative real-time PCR approach to determine safflower (Carthamus tinctorius) adulteration in saffron (Crocus sativus). Food Chemistry, 229, 680-687. https://doi.org/10.1016/j. foodchem.2017.02.136.

Xanthopoulou, A., Ganopoulos, I., Kalivas, A., Osathanunkul, M., Chatzopoulou, P., Tsaftaris, A., \& Madesis, P. (2016). Multiplex HRM analysis as a tool for rapid molecular authentication of nine herbal teas. Food Control, 60, 113-116. https://doi. org/10.1016/j.foodcont.2015.07.021.

Zhang, G., Liu, J., Gao, M., Kong, W., Zhao, Q., Shi, L., \& Wang, Q. (2020). Tracing the edible and medicinal plant Pueraria montana and its products in the marketplace yields subspecies level distinction using DNA barcoding and DNA metabarcoding. Frontiers in Pharmacology, 11, 336. https://doi.org/10.3389/fphar.2020.00336. 